\title{
Purchasing Strategy for Loss-aversion Manufacturer Based on Option Market
}

\author{
Wenyi Du, Xiaojing Liu* \\ Business School \\ Jiangsu Normal University \\ Xuzhou, China \\ xjliu@jsnu.edu.cn
}

\author{
Yubing $\mathrm{Fu}$ \\ AgriLife Research and Extension Center \\ Texas A\&M \\ Vernon, USA
}

\begin{abstract}
This paper studies the operation of purchase strategy for supply chain of loss-aversion manufacturer under the option market. The study shows that loss-aversion manufacturer does not behave positively in the option purchase, and the option order quantity decreases as the loss-aversion coefficient increases; the option execution proportion increases as the aversion coefficient of manufacturer increases. Through the comparative analysis of expected profit of system supply chain with option order adopted for both loss-aversion manufacturer and risk neutral manufacturer, it is found that the expected profit of system supply chain increases first and decreases later on as the loss-aversion coefficient of manufacturer increases, which is yet always larger than the expected profit of system supply chain for option purchase of risk neutral manufacturer. Finally, depending on numerical analysis, this paper validates the effectiveness of the conclusion.
\end{abstract}

Keywords-Purchasing strategy; Option market; Loss-aversion; Option purchase; Execution proportion

\section{INTRODUCTION}

The purchase of raw material is an important link of the corporate business activities, which will be easily affected by various factors such as inadequate capacity, fluctuation of market price and uncertain customer demand, result in high risk of the purchasing decision-making. According to statistics of IATA(International Air Transport Association), over 25 airlines with different scales all over the world declared bankruptcy or outage in the first half of 2008, and global airline business was facing loss of over USD 6.1 billion. The sudden and sharp rise and drop of international crude oil prices in 2008 (the international crude oil prices rose by $74 \%$ in the first half of 2008, and dropped by $75.5 \%$ in the second half of 2008) caused that some airlines carried out purchase of crude oil with the unreasonable method (increase or decrease the inventory), which exposed the airline business to the huge purchasing risk.

\section{LITERATURE REVIEW AND DESCRIPTION HYPOTHESES}

Through selection of different kinds of option contracts, the manufacturer can effectively reduce the purchasing risk, and maximize its benefit. For example, in order to reduce the comprehensive risk of purchase of plastics and other materials, and maximize the purchasing benefit, HP adopted $35 \%$ of option contracts for the purchase of materials(Billing,2002)[1] Schummer and Vohra [2]designed the optimal procurement strategy to solve the problem of the retailer under the

This research is supported by the Youth Project of Natural Science Foundation of China (grant number 71702067); the University Philosophy and Social Science Fund of Education Department of Jiangsu Province(grant number 2017SJB0975), Doctoral Funded Projects of Jiangsu Norma University(grant number 16XWR011,15XLR029).

* Correspondence: xjliu@jsnu.edu.cn circumstance of a group of given option contracts, and this paper assumed that the retailers are risk neutral. Wang and Liu [3]studied the option purchase model dominated by risk neutral retailers, to respectively find that the option contract could not realize coordination of supply chain; the risk sharing contract of supply chain is built, to realize the coordination between members of the supply chain. $\mathrm{Ma}, \mathrm{Hu}$ and $\mathrm{Lin}$ [4]studied the production capacity reservation model of supplier under the option contract, and found from analysis that the option contract can promote the transfer of supply chain information, and improve the role in coordination of supply chain. Chen [5] assumed the order decision of risk neutral retailers under two circumstance with option trading and without option trading, and the analysis showed that option order quantity and demand correlation coefficient of risk neutral retailers presented the decreasing function relation. Gomez-Padilla and Mishina [6] studied the impact of option contract on order strategy for distributors under two cases of single supplier and single distributor, multiple suppliers and single distributor. $\mathrm{Zhu}$ and $\mathrm{Hu}$ [7] studied the supply chain system composed of one manufacturer and one risk neutral distributor under the circumstance of uncertain demand market, established the supply chain decision-making model combining option contract and quantity flexibility contract. Wang, Li, Liang and Huang [8] considered a relief supply chain system, studied the purchasing with a buyback contract and instant-purchasing with a return policy, and found the option contract enables the coordination of a relief supply chain and the achievement of Pareto improvement.

In the above research on option contract, it is assumed that most of decision makers are risk neutral. However, under the circumstance that the supply of raw material market is uncertain, the risk exists objectively. Therefore, the risk neutral hypothesis of decision maker cannot absolutely characterize the decision-making behaviors of decision makers. Based on this, this paper studies the option order strategy for practical problems such as purchasing risk that the lossaversion manufacturers are facing in purchase of raw materials will be of practical significance, which can provide the strong guiding significance to the effective operation of the enterprises in semiconductor, aluminum and steel.

This paper studies the two-level supply chain system composed of one risk neutral supplier and one risk-aversion manufacturer, in which the manufacturer can purchase commodities from the supplier; in order to avoid the impact of fluctuation of market demand on purchasing strategy for the manufacturer, the manufacturer can first purchase an option 
contract. The supplier is leader and the manufacturer is follower. Assume that the marker demand $x$ is random variable, and its density function and distribution function are $f(x)$ and $F(x)$ respectively; $F(x)$ is continuously derivable; $F^{-1}(x)$ indicates the inverse function of probability distribution function of market demand, and $f(x) x /(1-F(x))$ is increasing function of $x$.

This paper used the loss-averse model prospect theory in prospect theory to characterize:

$$
U\left(\pi_{M}\right)= \begin{cases}\pi_{M}, & \pi_{M} \geq 0 \\ \lambda \pi_{M}, & \pi_{M}<0\end{cases}
$$

In (1), $\lambda$ refers to the loss-aversion coefficient of the manufacturer, $\lambda \geq 1$. When $\lambda>1$, it indicates the loss-aversion manufacturer; small $\lambda$ means low the degree of loss-aversion of the manufacturer; large $\lambda$ on the contrary, means high degree of loss-aversion of the manufacturer. When $\lambda=1$, it indicates the risk neutral manufacturer.

\section{MODELING}

At the first stage, the supplier $(c, K)$ first provides the option contract $\left(c_{0}, c_{e}\right)$ in the option market at certain premium, in which $c$ indicates the supplier's marginal cost for production of unit product; $K$ indicates the supplier's maximum supply quantity of the products; $c_{0}$ indicates the option price of unit product; $c_{e}$ indicates the option execution price of unit product; obviously, $c_{0}<c_{e}$;

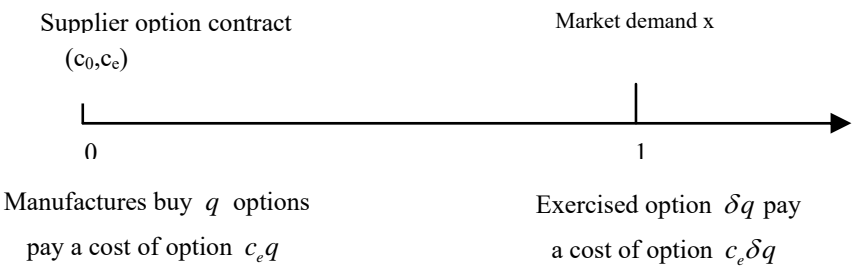

Fig. 1. Game model of both parties in supply chain system at two stages.

At the second stage, the manufacturer decides the product quantity $q$ ordered through this option contract at the point of 0 according to their own judgment on the market demand, and pays the option premium $c_{0} q$.

At the third stage, the manufacturer decides whether to execute this option at the point of 1 according to market demand $x$, and execution option quantity $\delta q$ and pay option execution premium $c_{e} \delta q$, in which $\delta \in(0,1] ; \delta$ indicates the execution option proportion of the manufacturer; game sequence is shown in Fig. 1.

At the fourth stage, the manufacturer has short product cycle without loss, and sells its products at the price of $p$ in the secondary market to earn the profit; the salvage value of surplus products of the manufacturer is $v$, and $p>c_{0}+c_{e}>c$.

\section{A. Centralized Decision-making}

For the centralized decision-making, both parties in supply chain system start from the overall interest as their own decision, and the overall interest of supply chain is

$$
\begin{aligned}
\pi_{C}=p \min & (q, x)-c K+v(q-x)^{+} \\
& = \begin{cases}p x-c K+v(q-x) & x<\delta q \\
p \delta q-c K & \delta q \leq x \leq K\end{cases}
\end{aligned}
$$

According to (2), the supply expected profit $E\left(\pi_{C}\right)$ of chain system is:

$$
\begin{aligned}
E\left(\pi_{C}\right)=\int_{0}^{+\infty} \pi_{C} f(x) d x= & \int_{0}^{\delta q}[p x-c K+v(\delta q-x)] f(x) d x \\
& +\int_{\delta q}^{+\infty}(p \delta q-c K) f(x) d x \\
= & (p \delta q-c K) F(K)-(p-v) \int_{0}^{\delta q} F(x) d x
\end{aligned}
$$

Solve first-order derivative and second-order derivative of $E\left(\pi_{c}\right)$ respectively according to (3), and obtain:

$$
\begin{gathered}
\partial E\left(\pi_{c}\right) / \partial q=p \delta F(K)-\delta(p-v) F(\delta q) \\
\partial^{2} E\left(\pi_{c}\right) / \partial q^{2}=-\delta^{2}(p-v) f(\delta q)<0
\end{gathered}
$$

It is known from (4) and (5) that $E\left(\pi_{c}\right)$ is concave function of option order quantity $q$; set $d E\left(\pi_{c}\right) / d q=0$, to obtain the internal problem of supply chain under the circumstance of centralized decision-making, and the optimal order quantity $q_{c}^{*}$ all the execution supply chain decision makers is:

$$
q_{c}^{*}=F^{-1}(p F(K) /(p-v))
$$

It is known from analysis of (6) that when option execution quantity $q<q^{*}$, the loss of expected profit of supply chain system is more if $q$ is smaller; when $q>q^{*}$, the loss of expected profit of supply chain system is more if $q$ is bigger.

Here, we get (7)-(9). And the expected profit of the suppliers is:

$$
E_{C}\left(\pi_{S}\right)=\left(c_{0}+c_{e}\right) q_{c}^{*}-c K
$$

The expected profit of the manufacturer is:

$$
\begin{aligned}
E_{C}\left(\pi_{M}\right)= & \left(p q_{c}^{*}-c K\right) F(K) \\
& -(p-v) \int_{0}^{q_{c}^{*}} F(x) d x-\left(c_{0}+c_{e}\right) q_{c}^{*}+c K
\end{aligned}
$$

The expected profit of supply chain system is:

$$
E_{C}\left(\pi_{C}\right)=\left(p q_{c}^{*}-c K\right) F(K)-(p-v) \int_{0}^{q_{c}^{*}} F(x) d x
$$




\section{B. Decentralized Decision-making}

In the supply chain system, we assume the Stackelberg game dominated by the suppliers and followed by the manufacturers, and solve it through the backward induction.

The profit function of the manufacturer is:

$$
\begin{aligned}
\pi_{M}(q)=p & \min (\delta q, x)-c_{0} q-c_{e} \delta q+v(\delta q-x)^{+} \\
& =\left\{\begin{array}{lr}
p x-c_{0} q-c_{e} \delta q+v(\delta q-x) & x<\delta q \\
p \delta q-c_{0} q-c_{e} \delta q & \delta q \leq x \leq K
\end{array}\right.
\end{aligned}
$$

In which, Item 1 on the right in profit function (10) indicates the sales revenue; Item 2 and Item 3 indicate the cost for purchase of raw materials through execution option; Item 4 indicates the salvage value of surplus products.

At this time, set $q^{0}$ as the execution option quantity of breakeven of the manufacturer(when the execution option quantity is at this point, the profit of the manufacturer is zero); set $\pi_{M}=0$ to obtain $q^{0}=\left(c_{0} q+c_{e} \delta q\right) / p$. When $x<q^{0}, \pi_{M}<0$; when $q^{0} \leq x \leq q, \pi_{M} \geq 0$; when $x>q, \pi_{M}>0$. Therefore, the expected loss $L_{M}$, expected profit $E\left(\pi_{M}\right)$ and expected utility $E\left(U\left(\pi_{M}\right)\right)$ of the manufacturer respectively are:

$$
\begin{aligned}
L_{M}=\int_{0}^{q^{0}} \pi_{M} f(x) d x & =\int_{0}^{q^{0}}\left[p x-c_{0} q-c_{e} \delta q+v(\delta q-x)\right] f(x) d x \\
& =-(p-v) \int_{0}^{q^{0}} F(x) d x
\end{aligned}
$$

$$
\begin{aligned}
E\left(\pi_{M}\right)= & \int_{0}^{K} \pi_{M} f(x) d x=\int_{0}^{\delta q}\left[p x-c_{0} q-c_{e} \delta q+v(\delta q-x)\right] f(x) d x \\
& \quad+\int_{\delta q}^{K}\left(p \delta q-c_{0} q-c_{e} \delta q\right) f(x) d x \\
= & \left(p \delta q-c_{0} q-c_{e} \delta q\right) F(K)-(p-v) \int_{0}^{\delta q} F(x) d x \\
E( & \left.U\left(\pi_{M}\right)\right)=\lambda \int_{0}^{q^{0}} \pi_{M} f(x) d x+\int_{q^{0}}^{K} \pi_{M} f(x) d x \\
= & (\lambda-1) \int_{0}^{q^{0}} \pi_{M} f(x) d x+\int_{0}^{q^{0}} \pi_{M} f(x) d x++\int_{q^{0}}^{K} \pi_{M} f(x) d x \\
= & E\left(\pi_{M}\right)+(\lambda-1) L_{M}
\end{aligned}
$$

According to (11)-(13), solve first-order partial derivative and second-order partial derivative of option order quantity $q$ and option execution proportion $\delta$ respectively, to obtain:

$$
\begin{array}{r}
\partial E\left(U\left(\pi_{M}\right)\right) / \partial q=\left(p-c_{0}-\delta c_{e}\right) F(K)-\delta(p-v) F(\delta q) \\
-\frac{c_{0}+\delta c_{e}}{p}(p-v)(\lambda-1) F\left(q^{0}\right) \\
\partial^{2} E\left(U\left(\pi_{M}\right)\right) / \partial q^{2}=-\delta^{2}(p-v) f(\delta q) \\
-\frac{\left(c_{0}+\delta c_{e}\right)^{2}}{p^{2}}(p-v)(\lambda-1) f\left(q^{0}\right)<0
\end{array}
$$

$$
\begin{gathered}
\partial E\left(U\left(\pi_{M}\right)\right) / \partial \delta=\left(p q-c_{e} q\right) F(K)-q(p-v) F(\delta q) \\
-\frac{c_{e} q}{p}(p-v)(\lambda-1) F\left(q^{0}\right)
\end{gathered}
$$

$$
\begin{aligned}
\partial^{2} E\left(U\left(\pi_{M}\right)\right) / \partial \delta^{2}=-q^{2}(p-v) f(\delta q) \\
-\left(c_{e} q / p\right)^{2}(p-v)(\lambda-1) f\left(q^{0}\right)<0
\end{aligned}
$$

It is known from (14)-(17) that $E\left(U\left(\pi_{M}\right)\right)$ is joint concave function of $q$ and $\delta$ :

$$
\left\{\begin{array}{l}
\left(p-c_{0}-\delta c_{e}\right) F(K)-\delta(p-v) F(\delta q)-\frac{c_{0}+\delta c_{e}}{p}(p-v)(\lambda-1) F\left(q^{0}\right)=0 \\
\left(p q-c_{e} q\right) F(K)-q(p-v) F(\delta q)-\frac{c_{e} q}{p}(p-v)(\lambda-1) F\left(q^{0}\right)=0
\end{array}\right.
$$

According to (18), the optimal can be obtained,

$$
\left\{\begin{array}{l}
q^{*}=\frac{1}{\delta^{*}} F^{-1}\left[\frac{p c_{e} F(K)-p F(K)-c_{e}(p-v)(\lambda-1) F(K) F\left(q^{0}\right)}{p(p-v)}\right] \\
\delta^{*}=1-\frac{p c_{0}-c_{0}(p-v)(\lambda-1) F\left(q^{0}\right)}{p^{2}}
\end{array}\right.
$$

Here, we get (20)-(22). And the expected profit of the supplier is:

$$
E\left(\pi_{s}\right)=\left(c_{0}+\delta^{*} c_{e}\right) q^{*}-c K
$$

The expected profit of the manufacturer:

$$
E\left(\pi_{M}\right)=\left(p \delta^{*} q^{*}-c_{0} q^{*}-c_{e} \delta^{*} q^{*}\right) F(K)-(p-v) \int_{0}^{\delta^{*} q^{*}} F(x) d x
$$

The expected profit of supply chain system is:

$$
\begin{aligned}
E\left(\pi_{C}\right) & =\left(p \delta^{*} q^{*}-c_{0} q^{*}-c_{e} \delta^{*} q^{*}\right) F(K) \\
& -(p-v) \int_{0}^{\delta^{*} q^{*}} F(x) d x+\left(c_{0}+\delta^{*} c_{e}\right) q^{*}-c K
\end{aligned}
$$

\section{OPTION ORDER QUANTITY OF NON-RISK-AVERSION MANUFACTURERS}

In order to better compare the impact of risk-aversion coefficient on option order quantity and expected profit of supply chain system, it is assumed that the manufacturer is risk neutral for decentralized decision-making of supply chain; the supplier gives option order combination $\left(c_{0}, c_{e}\right)$ of raw material purchase; the manufacturer decide the option order quantity as $q$; option execution proportion is decided as $\delta$ after market demand, sold at the price $p$ in the market.

$$
\begin{aligned}
\pi_{M}(q)=p & \min (\delta q, x)-c_{0} q-c_{e} \delta q+v(\delta q-x)^{+} \\
& =\left\{\begin{array}{lr}
p x-c_{0} q-c_{e} \delta q+v(\delta q-x) & x<\delta q \\
p \delta q-c_{0} q-c_{e} \delta q & \delta q \leq x \leq K
\end{array}\right.
\end{aligned}
$$


According to (23), the expected profit of risk neutral manufacturer is:

$$
\begin{aligned}
& E\left(\pi_{M}\right)=\int_{0}^{K} \pi_{M} f(x) d x= \int_{0}^{\delta q}\left[p x-c_{0} q-c_{e} \delta q+v(\delta q-x)\right] f(x) d x \\
&+\int_{\delta q}^{K}\left(p \delta q-c_{0} q-c_{e} \delta q\right) f(x) d x \\
&=\left(p \delta q-c_{0} q-c_{e} \delta q\right) F(K)-(p-v) \int_{0}^{\delta q} F(x) d x
\end{aligned}
$$

According to (24), solve first-order partial derivative and second-order partial derivative of $q$ and $\delta$ for $E\left(U\left(\pi_{M}\right)\right)$, to obtain:

$$
\begin{aligned}
& \partial E\left(\pi_{M}\right) / \partial q=\left(p-c_{0}-\delta c_{e}\right) F(K)-\delta(p-v) F(\delta q) \\
& \partial^{2} E\left(U\left(\pi_{M}\right)\right) / \partial q^{2}=-\delta^{2}(p-v) f(\delta q)<0 \\
& \partial E\left(\pi_{M}\right) / \partial \delta=\left(p q-c_{e} q\right) F(K)-q(p-v) F(\delta q) \\
& \partial^{2} E\left(\pi_{M}\right) / \partial \delta^{2}=-q^{2}(p-v) f(\delta q)<0
\end{aligned}
$$

It is known from (25)-(28) that $E\left(\pi_{M}\right)$ is joint concave function related to $q$ and $\delta$; therefore, for the option contract $\left(c_{0}, c_{e}\right)$ given by suppliers, $q$ and $\delta$ of option order quantity of the manufacturer are given by the following two:

$$
\left\{\begin{array}{l}
\left(p-c_{0}-\delta c_{e}\right) F(K)-\delta(p-v) F(\delta q)=0 \\
\left(p q-c_{e} q\right) F(K)-q(p-v) F(\delta q)=0
\end{array}\right.
$$

According to (29), the optimal option order quantity $q_{s}^{*}$ and optimal execution proportion $\delta_{s}^{*}$ of the manufacturer can be obtained, namely (30)

$$
\left\{\begin{array}{l}
q_{s}^{*}=\frac{p}{p-c_{0}} F^{-1}\left[\frac{\left(p-c_{e}\right) F(K)}{p-v}\right] \\
\delta_{s}^{*}=\frac{p-c_{0}}{p}
\end{array}\right.
$$

Here, we get (31)-(33), and the expected profit of the supplier is:

$$
E_{f}\left(\pi_{s}\right)=\left(c_{0}+\delta_{s}^{*} c_{e}\right) q_{s}^{*}-c K
$$

The expected profit of the manufacturer is:

$$
E_{f}\left(\pi_{M}\right)=\left(p \delta_{s}^{*} q_{s}^{*}-c_{0} q_{s}^{*}-c_{e} \delta_{s}^{*} q_{s}^{*}\right) F(K)-(p-v) \int_{0}^{s_{s}^{*} q_{s}^{*}} F(x) d x
$$

The expected profit of supply chain system is:

$$
\begin{aligned}
E_{f}\left(\pi_{C}\right) & =\left(p \delta_{s}^{*} q_{s}^{*}-c_{0} q_{s}^{*}-c_{e} \delta_{s}^{*} q_{s}^{*}\right) F(K) \\
& -(p-v) \int_{0}^{\delta_{s} q_{s}^{*}} F(x) d x+\left(c_{0}+\delta_{s}^{*} c_{e}\right) q_{s}^{*}-c K
\end{aligned}
$$

\section{NUMERICAL ANALYSIS}

Assume supply capacity of the supplier is $K=1000$, the output cost of raw materials is $c=2$; option combination is $c_{0}=2.5$, and $c_{e}=3$; repurchase price is $v=1$; sales price in the market is $p=10$; the market demand $x$ for the product follows the uniform distribution of $[0,1000]$, and its corresponding distribution function and density function are respectively:

$F(x)=x / 1000, f(x)=1 / 1000$.

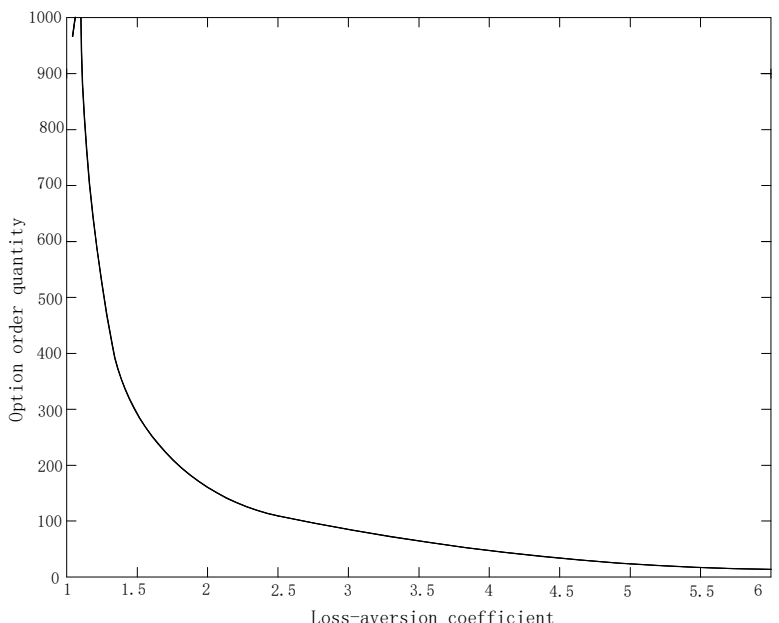

Fig. 2. The relationship between option order quantity and loss-aversion coefficient of manufacturer under the circumstance of decentralization.

Fig. 2 shows that under the circumstance of decentralization, the option order quantity of the manufacturer is decreasing function related to loss-aversion coefficient in case of loss-aversion, namely, the option order quantity decreases as the loss-aversion coefficient increases. It shows the manufacturer has higher and higher risk-aversion degree, and become more and more afraid of risk if the loss-aversion coefficient is larger; once there is a risk, the profits of the manufacturer must be affected, and the bankruptcy of the manufacturer may even be caused in series case. At this time, the manufacturer of loss-aversion will select conservative strategy, and seek stable option order quantity, but not take the risk.

Fig. 3 shows that under the circumstance of decentralization, the option execution proportion is increasing function related to loss-aversion coefficient in case of lossaversion, namely, the execution proportion increases as the bank interest increases. The higher execution proportion indicates the manufacturer is more optimistic about the future market, and the market performance is more and more active; people are full of expectations for future market. On the contrary, lower execution proportion indicates that the manufacturer loses confidence in the future market, and the 
market performance is more and more dull; people lose confidence in the future market.

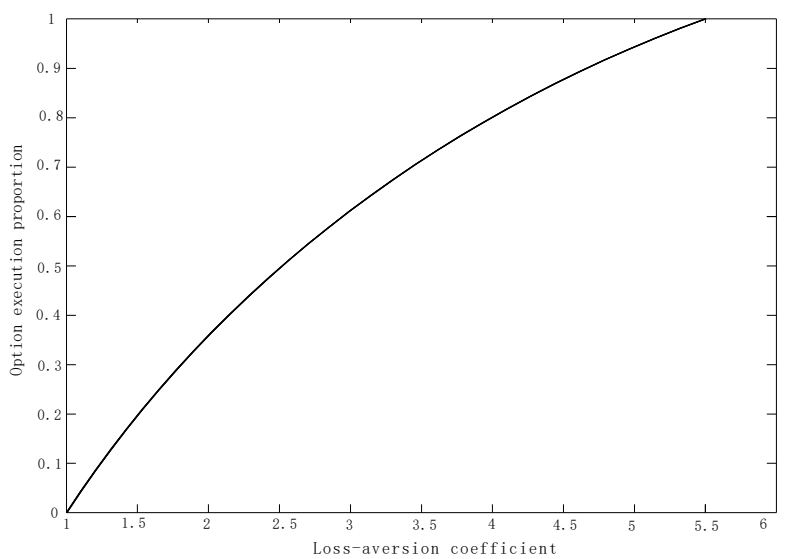

Fig. 3. The relationship between option execution proportion and lossaversion coefficient of manufacturer under the circumstance of decentralization.

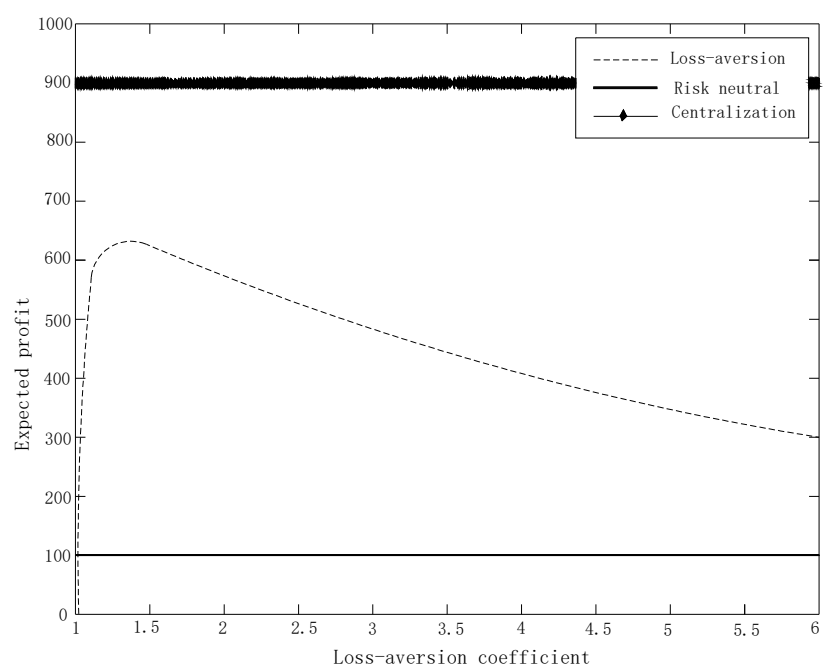

Fig. 4. The relationship between expected profit and loss-aversion coefficient under the circumstance of centralization and decentralization.

Fig. 4 shows that the loss-aversion coefficient does not affect the expected profit of supply chain system composed under two circumstances of centralization and risk neutral manufacturer, which obviously affects the expected profit of supply chain system composed of loss-aversion manufacturer

under the circumstance of decentralization, increasing first and decreasing then. When the market is in good trend and the expected profit is larger than the expected profit of supply chain composed of risk neutral manufacturer, the demand of manufacturer for raw materials increases, to increase the expected order quantity of manufacturers. Therefore, when the expected risk return is lower than profit of risk neutral supply chain, the loss-aversion manufacturer largely decrease the will of demand for raw materials, and affect the option order quantity of the manufacturer. On the contrary, the decision of traditional risk neutral manufacturer will perform rational response, and they will pay more attention to the absolute of option order quantity but not the variation value; at the same time, the attitude for risk-aversion is always held.

\section{CONCLUSION}

This paper found from research that the option order quantity decreases as the loss-aversion coefficient increases; option execution proportion increases as the aversion coefficient of the manufacturer increases. Finally, through comparative analysis of expected profit of supply chain system under two different circumstances of loss-aversion manufacturer and risk neutral manufacturer, it is found that the loss-aversion coefficient does not affect the expected profit of supply chain system composed under two circumstances of centralization and risk neutral manufacturer, but to largely affect the expected profit of supply chain system composed of loss-aversion manufacturer under the circumstance of decentralization, which increases first and decreases than, yet always larger than the expected profit of system supply chain for option purchase of risk neutral manufacturer.

Further research on the problems such as the impact of loss-aversion coefficient on the coordination of supply chain and capital restraint for the manufacturer will be discussed additionally.

\section{ACKNOWLEDGMENT}

We thank Dr. Fan give our guide and help with the paper.

\section{REFERENCES}

[1] T.C. Billing, "HP cuts risk with portfolio approach," Purchasing com, 2002.

[2] J.Schummer and R.V. Vohra "Auctions for procuring options," Operations Research, vol. 51(1), pp. 41-51, 2003.

[3] X. Wang and L. Liu, "Coordination in a retailer-led supply chain through option contract," International Journal of Production Economics, vol. 110(1/2), pp. 115-127, 2007.

[4] S.H. Ma, J.Y. Hu, and Y. Lin, “A Model for Supplier's Capacity Ordering with Options," Journal of Industrial Engineering/Engineering Management, vol. 18(1), pp. 8-11, 2004.

[5] X. Chen, "Retailer's procurement decisions for supply chain with options contracts," Journal of Management Sciences in China, vol. 9(3), pp. 17-23, 2006

[6] A. Gomez-Padilla and T. Mishina, "Supply contract with options," International Journal of Production Economics, vol. 122(1), pp. 312-318, 2009.

[7] H.B. Zhu and W. Hu, "Decision model of supply chain quantity flexibility contract with option," Control and Decision, vol. 29(5), pp. 860-866, 2014.

[8] X.H. Wang, F. Li, L. Liang, Z.M. Huang, and A. Allan, "Pre-purchasing with option contract and coordination in a relief supply chain," International Journal of Production Economics,vol. 167(9), pp. 170-176, 2015 . 